\title{
CRIMSONpublishers
}

http://www.crimsonpublishers.com

\section{Assessment of Aggression among Under19 Football Players}

\author{
Mohammad Amin Wani ${ }^{*}$, Sankar $\mathbf{R}^{1,}$ Beer Singh ${ }^{2}$ and Gayathri ${ }^{1}$ \\ ${ }^{1}$ Department of Psychology, Annamalai University, India \\ ${ }^{2}$ Department of Psychology, Chaudhary Charan Singh University, India \\ *Corresponding author: Mohammad Amin Wani, Department of Psychology, Annamalai University, Tamil Nadu, India \\ Submission: 望 August 24, 2017; Published: 望
}

\section{Abstract}

The present study aimed to find out the level of aggression among under 19 football players. The present study is based on the sample of 60 under 19 football players equally divided into two groups (boys and girls); further these two groups were also divided into two more sub groups as junior and senior selected through purposive sampling technique. Aggression in Sport and Business Questionnaire developed by R. Makarowski was used for data collection. Mean, Frequency, and t-test, was applied for statistical analysis. Results reveal that there is a significant difference found between the mean scores of aggression of boys and girls. But insignificant difference was found between the mean scores of junior and senior in respect to their aggression scores. Results also demonstrated that boys and junior player are more aggressive than girls and senior players. Further it is also revealed that 11(18.33\%) have high level of aggression, 46(76.67\%) have moderate level, and 3(5\%) players have low level of aggression (Table 2, Figure 1).

Keywords: Aggression; Football Players; Under19; Gender; Junior; Senior

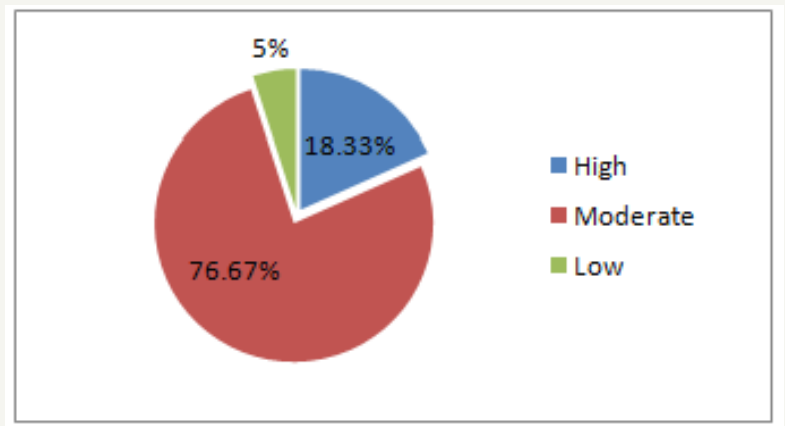

Figure 1: Graphical representation of level of Aggression among Respondents.

\section{Introduction}

Aggression is defined as any form of behavior directed toward the goal of harming or injuring another living being through words, action etc. In other words aggression can be defined as any behavior that is intended to cause physical or psychological harm to others. Dollard et al. [1] proposed the frustration aggression hypothesis, which held that aggression is always caused by frustration.

The Larousse dictionary of psychology defines aggression as tendency to attack physically or mentally to another living being [2]. Simultaneously the encyclopedic dictionary of psychiatry defines aggression as "a set of hostile behaviors which can occur in the conscious, unconscious or fantasmatic plan, in order to destroy, depreciate, constrain, deny or humiliate a person, an object invested with social significance or self-oriented" [3]. Aggression is one of the most potential dangers to mankind. It is a greatest stumbling block for one's self development and growth. Aggression is not only a behavior that hurt others; it is also complex emotional condition, with a specific cognitive structure and strong motivational base that involve the whole mental life [4].

Aggression in sports is defined into two main categories

a. Hostile aggression

b. Instrumental aggression

Hostile aggression is defined as hot impulsive angry behavior that is motivated to harm or injury another person, whereas, instrumental aggression is cold or premeditated behavior that is motivated by some other goal. In instrumental aggression the main goal is to be non aggressive but win the game, obtain money, or restore justice.

Many studies conformed that aggression is one of the areas to the most significant differences between genders. Gender has significant influence on hostile aggression [5]. It is also believed that females are more verbal aggressive, while as males have more physical aggression. Some researchers propose that differences in aggressive behavior can be observed by watching children at play. They conform that males are more likely to use mock fighting, unpleasant and tumble play, while as females tend to use indirect forms of aggression. This may incorporate such things as talking 
about or rejecting, avoiding, or ignoring, the objective of aggression. Male athletes and sportsperson are more aggressive than female athletes and sportspersons [1,6]; while as high achieving female athletes are more aggressive as compared to low achievers [7]. Simultaneously male sportspersons have high level of hostile aggression than female sportspersons [5]. Singh [8] affirmed that basketball players have high level of aggression than the volleyball players; also football players have high aggression level than hockey players [9]. On the other hand it is also confirmed that there is significant differences between the index of anger expression specific to the age of 17-18 years and the one specific to the athletes with 14-15 years old [10].

\section{Methodology}

\section{Objectives}

a. To find the level of aggression among boys and girls under19 football players.

b. To find the level of aggression among junior and senior under19 football players.

c. To find the level of all the three factors (Go Ahead, Tripping Someone Up and Assertiveness under 19 football players.

\section{Hypotheses}

a. There will be significant mean difference found between boys and girls under 19 football players.

b. There will be significant mean difference found between junior and senior under19 football players.

\section{Variables}

In the present study experimental variable is, aggression, criterion variables are gender, and category.

\section{Sample}

The present study was conducted on a sample of 60 under 19 foot ball players equally divided into two groups on the basis of gender (boys and girls). Further these two groups were also divided into two more sub groups on the basis of category as junior and senior selected through purposive sampling technique in Chidambaram Town of Cuddalore District of Tamil Nadu.

\section{Psychological Tools}

Aggression in Sport and Business Questionnaire developed by $\mathrm{R}$ Makarowski was used to measure the level of aggression among respondents. The questionnaire consisted 15 items with 5 responses in each item Absolutely Non, Rather Non, It is difficult to say, Rather Yes and Absolutely Yes scores as 1,2,3,4,5 respectively. The scale is divided into three dimensions
a. Go Ahead consist items $1,4,7,10,13$
b. Tripping Someone Up comprises items 2,5,8,11,14
c. Assertiveness comprises items: 3,6,9,12,15 respectively

Minimum score for each dimension is 5 and maximum score is
25 , simultaneously minimum and maximum scores of all items are 15 and 75 respectively.

\section{Procedure}

The study was conducted in Chidambaram Town of Cuddalore District of Tamil Nadu consisted a sample of 60 under 19 foot ball players selected through purposive sampling technique in Chidambaram Town of Cuddalore District of Tamil Nadu. The data was collected by Aggression in Sport and Business Questionnaire in Annamalai University Play ground. Prior to administrating the Questionnaire proper rapport was established with the respondents and they were information about purpose of study. After that Aggression in Sport and Business Questionnaire were distributed among them, during administration process those respondents were helped by the researcher who had difficulty in understanding the statements, after 20 minutes respondents hand over the questionnaire to the researcher and were thanked for their cooperation. Therefore the data was collected, after that obtained data was arranged in tabular form, then systematically analyzed by applying Mean, Frequency, and t- test, by using SPSS 20.0 version [11].

\section{Results}

The results of the present study are shown in the Table 1-6.

Table 1: Showing the distribution of respondents in respect to Gender, and Category.

\begin{tabular}{|c|c|c|c|c|}
\hline \multirow{2}{*}{ S.No } & \multicolumn{2}{|c|}{ Variable } & No & Percentage \% \\
\hline \multirow{2}{*}{1} & \multirow{3}{*}{ Gender } & Boys & 30 & 50 \\
\cline { 3 - 5 } & & Girls & 30 & 50 \\
\cline { 3 - 5 } & & Total & 60 & 100 \\
\hline \multirow{2}{*}{2} & \multirow{3}{*}{ Category } & Junior & 30 & 50 \\
\cline { 3 - 5 } & & Senior & 30 & 50 \\
\cline { 3 - 5 } & & Total & 60 & 100 \\
\hline
\end{tabular}

Table 2: Shows the level of Aggression among Respondents.

\begin{tabular}{|c|c|c|c|c|}
\hline S.No & Scores & No & Percentage \% & Levels \\
\hline 1 & $51-75$ & 11 & 18.33 & High \\
\hline 2 & $26-50$ & 46 & 76.67 & Moderate \\
\hline 3 & $15-25$ & 3 & 5 & Low \\
\hline Total & & 60 & 100 & \\
\hline
\end{tabular}

Table 3: Shows the level of Go-Ahead among Respondents.

\begin{tabular}{|c|c|c|c|c|}
\hline S.No & Scores & No & Percentage \% & Levels \\
\hline 1 & $19-25$ & 12 & 20 & High \\
\hline 2 & $12-18$ & 28 & 46.67 & Moderate \\
\hline 3 & $5-11$ & 20 & 33.33 & Low \\
\hline Total & & 60 & 100 & \\
\hline
\end{tabular}


Table 4: Shows the level of Tripping Someone Up among Respondents.

\begin{tabular}{|c|c|c|c|c|}
\hline S.No & Scores & No & Percentage \% & Levels \\
\hline 1 & $19-25$ & 15 & 25 & High \\
\hline 2 & $12-18$ & 31 & 51.67 & Moderate \\
\hline 3 & $5-11$ & 14 & 23.33 & Low \\
\hline Total & & 60 & 100 & \\
\hline
\end{tabular}

Table 5: Shows the level of Assertiveness among Respondents.

\begin{tabular}{|c|c|c|c|c|}
\hline S.No & Scores & No & Percentage \% & Levels \\
\hline 1 & $19-25$ & 14 & 23.33 & High \\
\hline 2 & $12-18$ & 27 & 45 & Moderate \\
\hline 3 & $15-11$ & 19 & 31.67 & Low \\
\hline Total & & 60 & 100 & \\
\hline
\end{tabular}

Table 6: Showing the Mean, S.D, SEM, and t- value of Aggression Scores of respondents.

\begin{tabular}{|c|c|c|c|c|c|c|c|}
\hline \multicolumn{2}{|c|}{ Variable } & No & Mean & S.D & S.E.M & df & t-value \\
\hline \multirow{2}{*}{ Gender } & Boys & 30 & 47.20 & 6.26 & 1.14 & \multirow{2}{*}{58} & \multirow{2}{*}{$7.07^{* *}$} \\
\cline { 2 - 8 } & Girls & 30 & 34.93 & 7.14 & 1.30 & & \\
\hline \multirow{2}{*}{ Category } & Junior & 30 & 41.70 & 9.46 & 1.72 & \multirow{2}{*}{58} & \multirow{2}{*}{0.54} \\
\cline { 2 - 7 } & Senior & 30 & 40.43 & 8.81 & 1.60 & & \\
\hline
\end{tabular}

**Significance at 0.01 levels.

\section{Discussion}

The results of the present study demonstrated that majority of the players have aggression level. Results revealed that male football players have high level of aggression than female players, similarly junior player are more aggressive than senior players. The mean scores of male players were more than the mean scores of female players. Simultaneously mean scores of junior players was more than the mean scores of senior players. Further it is also revealed that $11(18.33 \%)$ have high level, $46(76.67 \%)$ have moderate level, and $3(5 \%)$ players have low level of aggression.

Results also confirmed that majority of the players have moderate level of go ahead tendency, Tripping Someone up, and Assertiveness. Table 3 that $12(20 \%)$ players have high, 28(46.67\%) have moderate, and 20(33.3\%) have low level of go ahead tendency. Considering the tripping someone up tendency (Table 4) 15(25\%) have high, 31(51.67\%) have moderate, and 14(23.33\%) have low level. Simultaneously (Table 5) 14(23.33\%) have high, 27(45\%) have moderate, and $19(31.67 \%)$ have low level of assertiveness tendency.

Considering the results on the basis of gender it was found that there is a significant mean difference between the mean scores of male and female football players, as obtained t-value (7.07, $\mathrm{df}$ 58) was found significant at 0.01 level. Mean, S.D, and SEM of the same group was found [Boys ( $M=47.20, S . D=6.26, S E M=1.14)$, Girls $(M=34.93, S . D=7.14, S E M=1.30]$ respectively (Figure 2). Therefore the first hypothesis is accepted, thus on the basis of our findings we can say that boys are more aggressive then girls. Our findings got the solid background and support by Baird [3], Kumar [6], Pande \& Jaiswal [10] they found the same results in their research.

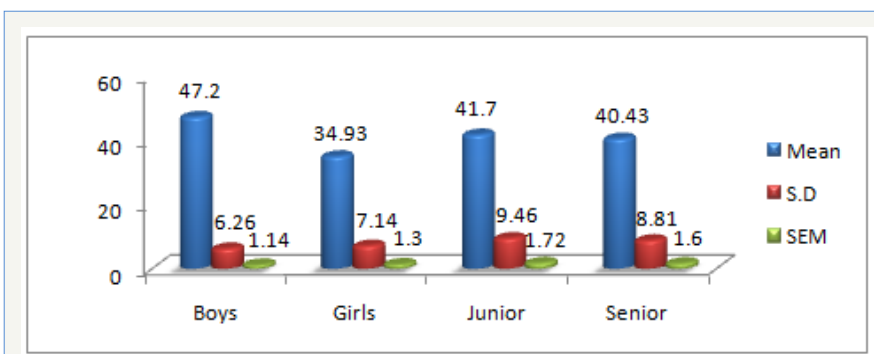

Figure 2: Graphical representation of Mean, S.D, and SEM of respondents.

Further findings divulge that there is no significant mean difference found between junior and senior football players as the $\mathrm{t}$-value $(0.54, \mathrm{df} 58)$ was found insignificant at 0.05 level. Mean, S.D, and SEM of the same group was found [Junior (M=41.70, S.D=9.46, $\mathrm{SEM}=1.72)$, Senior $(M=40.43, \mathrm{~S} . \mathrm{D}=8.81, \mathrm{SEM}=1.60]$ respectively. Hence the second hypothesis is partially rejected.

\section{Conclusion}

On the basis of findings it is affirmed that male and junior under19 football players are more inclined to aggression than female and senior players. Significant mean difference was also found between boys and girls in respect to their aggression. Simultaneously insignificant mean difference was found between the aggression scores of junior and senior under19 football players. Results also revealed that $18.33 \%$ have high level of aggression, $76.67 \%$ have moderate level, and 5\% players have low level of aggression.

\section{References}

1. Dollard, John Miller, Neal ED, Leonard WM, Sears OH, et al. (1939) Frustration and aggression. New Haven: Yale University Press, USA.

2. Sillamy N (1998) Larousse dictionary of psychology Editura Univers Enciclopedic.

3. Gorgos C (1987) Encyclopedic dictionary of psychiatry, București: Editura Medicală.

4. Stemate R (2009) Experiential module focused on developing aggressiveness management skills in adolescents. Editura SPER.

5. Kumar S (2016) Study of hostile aggression in male and female sports person. International Journal of Physical Education, Sports and Health 3(3): 444-446.

6. Pande A, Jaiswal DT (2017) Aggression and success orientation among sportspersons: gender specific analysis. International Journal of Researches in Biosciences. Agriculture \& Technology 5: 1-3.

7. Mishra V (2001) Assessment of aggression and anxiety among players of selected sports. Indian Journal of Sports Studies 6(2): 24-27.

8. Singh T (2017) Comparative study of aggression between basketball and volleyball players. European Journal of Physical Education and Sport Science 3(4): 56-64.

9. Singh K, Kerketta I (2015) A comparative study of aggression between football and hockey players of Bilaspur. International Journal of Physical Education. Sports and Health 1(6): 133-134.

10.Oproiu I (2013) A study on the relationship between sports and aggression. Sport Science Review 22(1-2): 33-48.

11. Baird SM (2009) Meaning to me: A symbolic interactions approach to aggression in sport psychology. Quest 61(4): 377-396. 